\title{
EXHIBITION
}

\section{How faces share feelings}

\section{Jascha Hoffman}

Forty years ago, psychologist Paul Ekman took his camera to the island of New Guinea to photograph the faces of the South Fore people. He wanted to prove that the expressions on their faces did not mirror social convention but were universal displays of human emotion. A set of these photographs, which launched Ekman's long career deciphering the secrets of the human face, is now on display in the new Mind exhibition at San Francisco's Exploratorium.

In the 1960s, many anthropologists thought that a smile could convey joy in one culture and disgust in another. Ekman had a hunch that this relativistic thinking was wrong. Almost a century before, Charles Darwin had conducted his own international survey of facial expressions in the belief that they were universal. Inspired by this approach, Ekman secured military funding for a series of experiments that showed that people from Japan and Chile, among others, could read expressions on North American faces. When the American anthropologist Margaret Mead protested that exposure to magazines and films might have obscured the differences between cultures, Ekman set out to test the most isolated humans he could find. "I needed to study people who had never had contact with the outside world," he explained. "I wanted to settle it decisively."

When he arrived in New Guinea, there were some misunderstandings. Ekman's attempt, recorded on film, to inspire fear by lunging at a South Fore boy with a rubber knife caused nothing but laughter. After this experiment failed, he had to hand out cigarettes and soap to get people to take part in further ones. Yet when participants were asked to point to a pictured face that matched the emotion evoked by a particular story - anger, disgust, fear, joy, sadness or surprise - they made the same associations as people living elsewhere. There was one exception. The South Fore peo-

ple did not distinguish between fear and surprise. Ekman now speculates that they may have had trouble telling these two emotions apart because, as he says: "In that culture, anything totally unexpected is going to be threatening."

ince his South Fore study, Ekman has found only one more emotion with a universal expression: contempt. Some other emotions, such as guilt, shame and interest, have not been added to the list of universals because they are expressed in different ways even in the same culture. One might expect some expressions to be learned by mimicry, but Ekman cites evidence to the contrary: psychologist David Matsumoto found that blind judo wrestlers show the thrill of victory and conceal the agony of defeat in precisely the same ways that sighted athletes do. "It's not something we have to learn by observing others," Ekman says. "It's got to be stored in the brain. Nobody knows where."

Ekman went on to devise a Ekman went on to devise a
stem to classify facial expressions using the movements of 43 muscles in the face. He discovered that hidden emotions, such as those caused by lying, can be revealed by fleeting 'microexpressions. His system is now used by computer animators to create realistic facial animations and by police officers interviewing suspects. Ekman is also working with the US Department of Homeland Security to train airport staff to identify potential hijackers by searching for suppressed fear and disgust in passengers' faces.

One item in the exhibition stands out. A tiny video screen shows Ekman's 1967 footage of a group of boys playing outside the window of his hut in New Guinea. After disappearing from view, a young boy suddenly sticks his head back into the frame and pulls faces at the camera. The scene is so familiar, yet, after one has paid such close attention to facial detail, it seems utterly foreign. It is a reminder of how flexible our faces are, and of how much we can convey when we know someone is watching.

Jascha Hoffman is a writer based in New York City.

\section{The Search for Universals in Human Emotion:} Photographs from the New Guinea Expedition runs until 11 May at The Exploratorium, San Francisco, California.

\section{EXHIBITION}

\section{An eye for detail}

\section{Jenny Meyer}

Maria Sibylla Merian is one of the most significant seventeenthcentury artists of natural history. Her carefully observed records of plants, insects and animals are on display at the Rembrandt House Museum in Amsterdam until May, moving to the Getty Center in Los Angeles, California, in June.

Showing her as both scientist and artist, the exhibition Maria Sibylla Merian \& Daughters: Women of Art and Science offers glimpses of Merian's methods, and includes mounted insects in varying states of metamorphosis. The collection is interspersed with paintings and prints by other artists who influenced her, including her stepfather and teacher, Jakob Marrel.

Merian led an unconventional life. Aged 38 and already the author of two books on caterpillars and a three-volume set on flowers, she left her husband and entered a religious commune with her two daughters. Five years later, she and her daughters moved to Amsterdam and established a business selling artists' materials alongside preserved insects and animals.

In 1699, Merian travelled to Suriname (then a Dutch colony) in South America with her youngest daughter, Dorothy, and stayed there for two years to observe and record life in the tropical

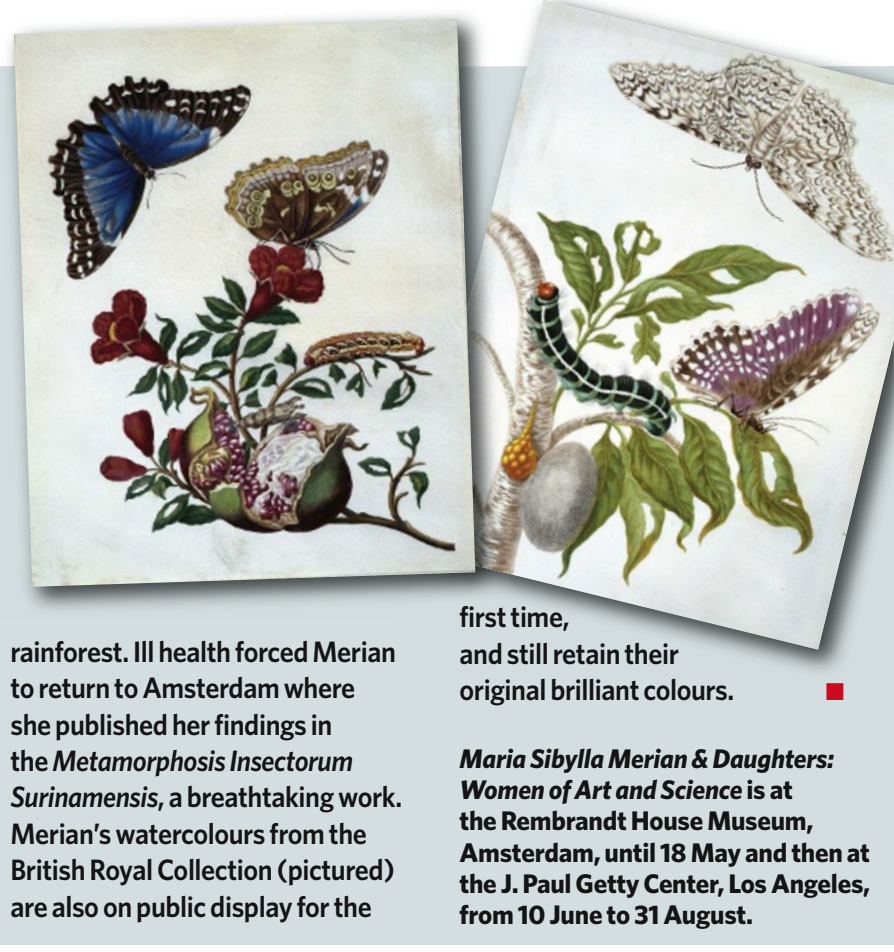

